Chronic Obstructive Pulmonary Diseases:

Journal of the COPD Foundation

\author{
Original Research
}

\title{
Challenges Faced by Rural Primary Care Providers When Caring for COPD Patients in the Western United States
}

Fernando Diaz del Valle, MD ${ }^{1 *}$ Patricia B. Koff, RRT, MEd ${ }^{1 *}$ Sung-Joon Min, $\mathrm{PhD}^{2}$ Jonathan K. Zakrajsek, $\mathrm{MS}^{1}$ Linda Zittleman, $\mathrm{MS}^{3}$ Douglas H. Fernald, $\mathrm{MA}^{3}$ Andrea Nederveld, $\mathrm{MD}^{3}$ Donald E. Nease, $\mathrm{MD}^{3}$ Alexis R. Hunter, BS ${ }^{4}$ Eric J. Moody, $\mathrm{PhD}^{5}$ Kay Miller Temple, $\mathrm{MD}^{6}$ Jenny L. Niblock ARNP, DNP Chrysanne Grund, BS ${ }^{7}$ Tamara K. Oser, $\mathrm{MD}^{3} \mathrm{~K}$. Allen Greiner, $\mathrm{MD}^{7} \mathrm{R}$. William Vandivier, $\mathrm{MD}^{1}$

\section{Abstract}

Rationale: Rural chronic obstructive pulmonary disease (COPD) patients have worse outcomes and higher mortality compared with urban patients. Reasons for these disparities likely include challenges to delivery of care that have not been explored.

Objective: To determine challenges faced by rural primary care providers when caring for COPD patients.

Methods: Rural primary care providers in 7 primarily western states were asked about barriers they experienced when caring for COPD patients.

Results: A total of 71 rural primary care medical providers completed the survey, of which $51 \%$ were physicians and $49 \%$ were advanced practice providers (APPs). A total of $61 \%$ used Global Initiative for Chronic Obstructive Lung Disease or American Thoracic Society/European Respiratory Society guidelines as an assessment and treatment resource. The presence of multiple chronic conditions and patient failure to recognize and report symptoms were the greatest barriers to diagnose COPD. A total of $89 \%$ of providers used spirometry to diagnose COPD, but only $62 \%$ were satisfied with access to spirometry. Despite recommendations, $41 \%$ of providers never test for alpha-1 antitrypsin deficiency. A total of $87 \%$ were comfortable with their ability to assess symptoms, but only $11 \%$ used a guideline-recommended assessment tool. Although most providers were satisfied with their ability to treat symptoms and exacerbations, only $66 \%$ were content with their ability to prevent exacerbations. Fewer providers were happy with their access to pulmonologists (55\%) or pulmonary rehabilitation (37\%). Subgroup analyses revealed differences based on provider type (APP versus physician) and location (Colorado and Kansas versus other states), but not on population or practice size.

Conclusions: Rural providers face significant challenges when caring for COPD patients that should be targeted in future interventions to improve COPD outcomes.

\footnotetext{
Abbreviations: chronic obstructive pulmonary disease, COPD; advance practice providers, APPs; rural practice-based research networks, PBRNs; state offices of rural health, SORHs; nurse practitioner, NP; physician assistant, PA; COPD Assessment Test, CAT; modified Medical Research Council, mMRC; Research Electronic Data Capture, REDCap; Federally Qualified Health Centers, FQHC; rural health clinics, RHC; Global initiative for chronic Lung Disease, GOLD; American Thoracic Society, ATS; European Respiratory Society, ERS; coronavirus disease 2019, COVID-19

Funding Support: This study was funded by the National Institutes of Health (HL129938-03) and by the reserve account for author RWV. Date of Acceptance: May 6, 2021 | Published Online Date: May 28, 2021

Citation: Diaz del Valle F, Koff PB, Min SJ, et al. Challenges faced by rural primary care providers when caring for COPD patients in the western United States. Chronic Obstr Pulm Dis. 2021;8(3):336-349. doi: https://doi.org/10.15326/jcopdf.2021.0215
} 
1 Division of Pulmonary Sciences and Critical Care Medicine, Denver Anschutz Medical Campus, University of Colorado, Aurora, Colorado, United States

2 Department of Medicine, Division of Healthcare Policy and Research, Denver Anschutz Medical Campus, University of Colorado, Aurora, Colorado, United States

3 Department of Family Medicine, Denver Anschutz Medical Campus, University of Colorado, Aurora, Colorado, United States

4 High Plains Research Council Community Advisory Council, Denver Anschutz Medical Campus, University of Colorado, Aurora, Colorado, United States

5 Wyoming Institute for Disabilities, University of Wyoming, Laramie, Wyoming, United States

6 Center for Rural Health, University of North Dakota School of Medicine and Health Sciences, Grand Forks, North Dakota, United States

7 Department of Family Medicine and Community Health, University of Kansas Medical Center, Kansas City, Kansas, United States

* Contributed equally to the manuscript.

\section{Address correspondence to:}

R. William Vandivier, MD

Division of Pulmonary Sciences and Critical Care Medicine

University of Colorado Denver

12700 E 19th Ave, Campus Box C272

Aurora, CO 80045

Phone: (303)724-6068

E-mail: Bill.Vandivier@cuanschutz.edu

\section{Keywords:}

health care delivery; guidelines; symptom assessment; COPD

Assessment Test; primary care

\section{This article has an online data supplement.}

\section{Introduction}

In the United States, chronic obstructive pulmonary disease (COPD) is the 4th leading cause of death, affects over 15 million people, ${ }^{1-3}$ and is nearly twice as common in rural versus urban areas (i.e., $8.2 \%$ versus $4.7 \%)^{2,4-6}$ The problem is even worse in economically distressed areas where the prevalence of COPD climbs ${ }^{7}$ to as high as $15.7 \%$. The higher prevalence of smoking in rural areas is undoubtedly one of the prime causes for this urban/rural disparity. ${ }^{8,9}$ But in rural America, COPD is also 34\% more common among never smokers, suggesting that exposure to fine particulates from other sources (e.g., secondhand cigarette smoke and dusts from agricultural, industrial, and biomass fuels) plays an important role in disease pathogenesis. ${ }^{7}$

COPD takes a greater toll in rural areas of the country where it results in more exacerbations ${ }^{10}$ and hospitalizations, ${ }^{2}$ worse quality of life, ${ }^{11}$ and higher mortality. ${ }^{2,12}$ In contrast to other major causes of death, COPD-related mortality continues to rise in the rural United States at the same time that it is falling in urban areas. ${ }^{13}$ The reasons why rural outcomes for COPD are worse than urban are complex and likely to include ongoing occupational and home exposures, as well as barriers to access and delivery of medical care. $^{13-20}$

Nationwide, approximately $80 \%$ of COPD patients are under the care of a primary care medical provider. ${ }^{21}$ Given the paucity of pulmonary specialists in rural areas, ${ }^{16,17}$ the role of rural primary care medical providers in COPD care is likely to be even more important. ${ }^{20,22}$ Studies have explored the barriers faced by primary care providers when caring for COPD patients nationally. ${ }^{23-26}$ But to our knowledge, limited attention has been given to the challenges faced by rural medical providers, ${ }^{20}$ and a comprehensive study has not been performed. A group of pulmonary specialists, rural primary care providers, and a rural community advisory council that included lay members created, "The Rural Medical Provider COPD Survey." The survey was administered by email to rural medical providers in 7 states through rural practice-based research networks (PBRNs) at the University of Colorado and the University of Kansas, and through state offices of rural health (SORHs) in Nevada, Utah, Wyoming, North Dakota, and Arizona. ${ }^{27}$

\section{Methods}

\section{Study Design}

The Rural Medical Provider COPD Survey received exempt status by the Colorado Multiple Institutional Review Board (COMIRB Protocol 19-2016) and was distributed to rural medical providers from September 10, 2019 through April 2, 2020.

Participants were identified through PBRNs affiliated with the State Networks of Colorado Ambulatory Practices and Partners at the University of Colorado (i.e., High Plain Research Network, Colorado Research Network, and Partners Engaged in Achieving Change in Health Network) and the University of Kansas (i.e., Kansas Patients and Providers Engaged in Prevention Research). They were also identified through SORHs in Nevada, Utah, Wyoming, North Dakota, and Arizona. ${ }^{27}$ Participants 
were included in the study if they identified themselves as a rural medical provider and were excluded if they did not. We asked participating organizations to send the survey to physicians with an $\mathrm{MD}$ or $\mathrm{DO}$ degree or to advanced practice providers (APPs) with a nurse practitioner (NP) or physician assistant (PA) degree. Participants were invited to take part in the study through newsletters and emails sent by each organization.

\section{Survey}

The Rural Medical Provider COPD Survey contained 26 questions and sub-questions (see online supplement) that were designed to collect demographic data and to determine rural medical providers' satisfaction with their practices' ability to diagnose, assess, and treat COPD, and to access ancillary services. After confirming rurality by selfreport, questions 1-5 asked about the use of COPD guidelines, diagnosis of COPD, and how participants prefer to access educational information. Questions 1-4 were taken directly from 2 national surveys of primary care providers by Yawn and colleagues. ${ }^{23,24}$ Questions 6-9 asked about providers' satisfaction with their practices' ability to assess and treat COPD patients, access ancillary services, and whether their practice measured alpha-1 antitrypsin levels or used guideline-recommended assessment tools, such as the COPD assessment test (CAT) or the modified Medical Research Council (mMRC) Dyspnea Scale. The remaining questions collected demographic information related to providers, their practice, and the presence of an office spirometer.

\section{Survey Administration}

PBRNs and SORHs were contacted and asked to distribute the survey to rural medical providers within their network with 1 reminder email. PBRNs in Colorado and Kansas delivered the survey to providers in their network via newsletters and email. SORHs delivered surveys via emails. The newsletter or email included a summary of the survey goal, a consent statement along with information on how to connect electronically with the survey by hyperlink, web address, or QR code. Participants were also provided with an electronic copy of the survey to complete and mail in, but this method was not utilized. Participants were not compensated for their time. The Research Electronic Data Capture (REDCap) platform was used to collect survey data for analysis. ${ }^{28}$

\section{Statistical Methods}

Descriptive statistics were reported as frequencies and percentages. Differences between subgroups were compared with chi-square tests (or Fisher Exact Tests when cell counts were small). A significance level of 0.05 was used for all tests. SAS v9.4 (SAS Institute, Cary, North Carolina) was used for analysis.

\section{Subgroup Analyses}

The study performed analyses to determine whether there were survey response differences based upon training (i.e., physicians versus APPs), practice location (i.e., Colorado and Kansas versus Other States), medically underserved communities (i.e., Federally Qualified Health Centers [FQHC] and rural health clinics [RHC]) versus private or hospitalbased), or practice size (i.e., $\leq 5$ providers versus $>5$ providers).

\section{Sample Size Calculations}

Approximately 1200 providers were available for the survey, with potential response rates ranging from $3 \%-10 \%$ for an email survey with no incentives. ${ }^{29}$ Descriptive statistics were utilized to compile and analyze the survey results. National studies of primary care physicians and AAPs show that 45\%-50\% use COPD guidelines. ${ }^{23,24}$ Based on these data, $\mathrm{N}=110$ participants would be needed to show a \pm 10 percentage point accuracy using 95\% confidence intervals of $(35.2 \%, 54.8 \%)$ to $(40.02 \%, 59.8 \%)$, or $\mathrm{N}=410$ participants to show a \pm 5 percentage point accuracy using $95 \%$ confidence intervals of $(40.1 \%$, $49.9 \%)$ to $(45.04 \%, 54.96 \%)$.

\section{Results}

Of the estimated 1018 rural medical providers that had access to the survey through email and newsletters, $8 \%$ responded $(n=77)$. A total of 71 identified themselves as rural medical providers and were included in the analysis. Some results were condensed to simplify figures and tables.

\section{Demographics}

Providers in the Total Cohort tended to be younger (i.e., < 50 years old) and to have been in practice for fewer years (i.e., $\leq 15$ years) (Table 1 ). Providers were divided by degree into physicians with an $\mathrm{MD}$ or $\mathrm{DO}$, and APPs with an NP or PA. We included 2 providers in the APP groups who chose "other" for their highest 


\section{Table 1. Demographics ${ }^{a}$}

\begin{tabular}{|c|c|c|c|c|c|c|c|c|}
\hline \multirow[t]{2}{*}{ Characteristic } & \multirow{2}{*}{$\begin{array}{c}\text { Total } \\
\text { Cohort } \\
\begin{array}{c}\mathrm{N}=71 \\
(100 \%)\end{array}\end{array}$} & \multicolumn{3}{|c|}{ Provider Degree } & \multicolumn{4}{|c|}{ Practice Location } \\
\hline & & $\begin{array}{l}\text { MD/DO } \\
\begin{array}{l}\text { N=36 } \\
(51 \%)\end{array}\end{array}$ & $\begin{array}{l}\text { APP } \\
\begin{array}{l}N=35 \\
(49 \%)\end{array}\end{array}$ & $p$-value & Colorado & Kansas & $\begin{array}{l}\text { Other } \\
\text { States }\end{array}$ & $p$-value \\
\hline Age, $y$ & & & & 0.54 & & & & 0.70 \\
\hline$<50$ & $40(56)$ & 19 (53) & $21(60)$ & & 17 (49) & $13(76)$ & $10(53)$ & \\
\hline$\geq 50$ & $31(44)$ & $17(47)$ & $14(40)$ & & $18(51)$ & $4(24)$ & $9(47)$ & \\
\hline Degree & & & & & & & & 0.69 \\
\hline $\mathrm{MD} / \mathrm{DO}$ & $36(51)$ & $36(100)$ & $0(0)$ & & $18(51)$ & $8(47)$ & $10(53)$ & \\
\hline $\mathrm{NP} / \mathrm{PA}$ & $33(46)$ & $0(0)$ & $33(94)$ & & $16(46)$ & $8(47)$ & $9(47)$ & \\
\hline Other & $2(3)$ & $0(0)$ & $2(6)$ & & $1(3)$ & $1(6)$ & $0(0)$ & \\
\hline Rural Practice, y & & & & 0.66 & & & & 0.63 \\
\hline$\leq 15$ & $41(59)$ & $22(61)$ & $19(56)$ & & $18(51)$ & $11(69)$ & $12(63)$ & \\
\hline$>15$ & $29(41)$ & $14(39)$ & $15(44)$ & & $17(49)$ & $5(31)$ & $7(37)$ & \\
\hline Total Providers per Practice & & & & 0.72 & & & & 0.03 \\
\hline$\leq 5$ & $37(52)$ & $18(50)$ & $19(54)$ & & $17(49)$ & $6(35)$ & $14(74)$ & \\
\hline$>5$ & $34(48)$ & $18(50)$ & $16(46)$ & & $18(51)$ & $11(65)$ & $5(26)$ & \\
\hline Practice Type & & & & 0.52 & & & & 0.33 \\
\hline RHC/FQHC/IHS & $44(62)$ & $21(58)$ & $23(66)$ & & $23(66)$ & $11(65)$ & $10(53)$ & \\
\hline Private/Hospital/Health System & $27(38)$ & $15(42)$ & $12(34)$ & & $12(34)$ & $6(35)$ & $9(47)$ & \\
\hline Practice Location & & & & 0.94 & & & & \\
\hline Colorado & $35(49)$ & $18(50)$ & $17(49)$ & & $35(100)$ & $0(0)$ & $0(0)$ & \\
\hline Kansas & $17(24)$ & $8(22)$ & $9(26)$ & & $0(0)$ & $17(100)$ & $0(0)$ & \\
\hline $\begin{array}{l}\text { Other States (Nevada, Utah, } \\
\text { Wyoming, North Dakota, } \\
\text { Arizona) }\end{array}$ & $19(27)$ & $10(28)$ & $9(26)$ & & $0(0)$ & $0(0)$ & $19(100)$ & \\
\hline
\end{tabular}

a Data are presented as n (\%). Percentages may not total $100 \%$ due to rounding.

$P$-values shown for comparison between MD/DO and APP groups or between Colorado and Kansas combined versus Other States. Chi-square tests (or *Fisher's Exact tests) were used to compare groups.

$\mathrm{MD}=$ Doctor of Medicine; DO=Doctor of Osteopathic Medicine; APP=advanced practice providers (NP/PA/Other); NP=nurse practitioner; $\mathrm{PA}=$ physician assistant; $\mathrm{RHC}=$ rural health clinic; $\mathrm{FQHC}=$ Federally Qualified Health Center; IHS=Indian Health Service

degree, because they identified themselves as a rural medical provider and indicated that their highest degree was a Masters. Half of the providers were physicians, and the other half were APPs, comparably split between NPs (51\%) and PAs (46\%). Practices were also evenly divided between those with $\leq 5$ and $>5$ providers per practice. Sixty-two percent of providers practiced in RHCs (39\%), FQHCs (21\%) or in the Indian Health Service (1\%). The other 38\% of providers practiced in private (20\%) or hospital/ health system (18\%) settings. Forty-nine percent of providers surveyed practiced in Colorado, $24 \%$ in Kansas, and $27 \%$ in the Other States group, including
Nevada, Utah, Wyoming, North Dakota, and Arizona.

\section{COPD Guidelines and Diagnosis}

Figure 1 and Supplementary Table 1 (in the online supplement) include responses to questions aimed at determining provider use of COPD guidelines, barriers to the diagnosis of COPD, and how providers typically make the diagnosis of COPD. Sixty-one percent of providers reported using Global initiative for chronic Obstructive Lung Disease (GOLD) ${ }^{30}$ (55\%) or American Thoracic Society (ATS)/ European Respiratory Society (ERS) ${ }^{31}$ (6\%) COPD guidelines as a resource to diagnose and manage 


\section{Figure 1. Total Cohort COPD Guidelines, Diagnosis, and Assessment}

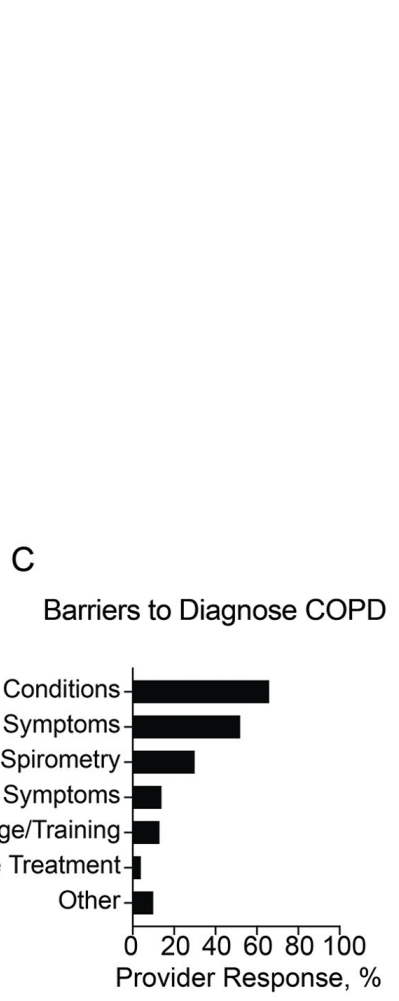

A

Use

COPD Guidelines

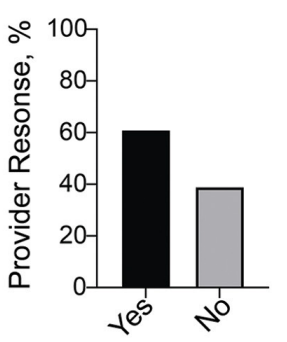

Provider Response, \%
B

Prefer

Electronic Information

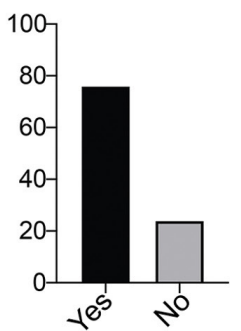

Failure to Report Symptoms

Lack of Access to Spirometry

Lack of COPD Symptoms

Lack of Knowledge/Training

Lack of Effective Treatment-

D

How to Diagnose COPD

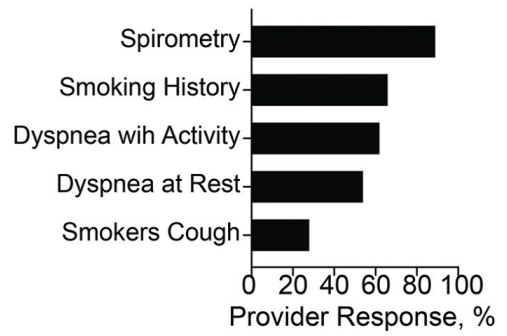

E

Diagnostic Tests for COPD

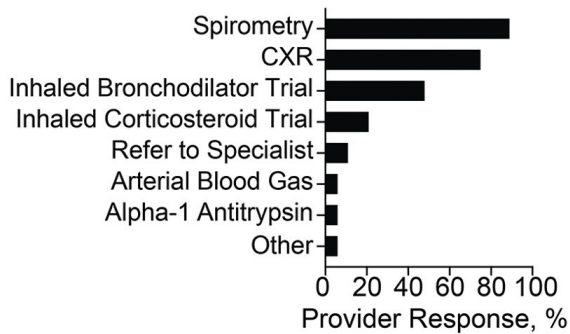

\section{$\mathrm{F}$}

Satisfied with

Symptom Assessment

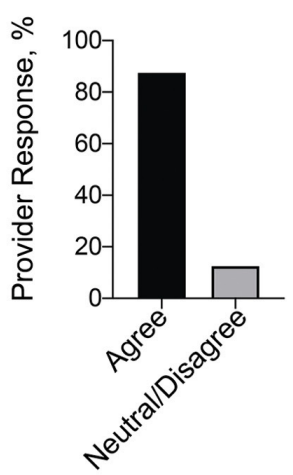

G Use
CAT or mMRC

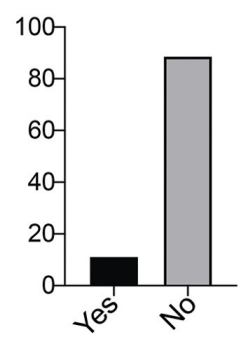

$\mathrm{H}$ Satisfied with Access to Spirometry

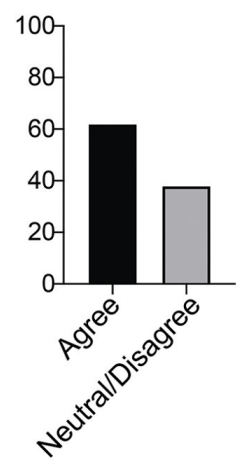

I

Have an Office Spirometer

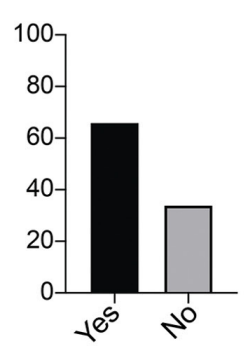

$J$

Test for Alpha-1 Antitrypsin

Survey questions are shown graphically as yes/no responses or after combining agree/strongly agree answers into the "agree" column and neutral/disagree/ strongly disagree answers into the "neutral/disagree" column. Answers are shown for questions related to: (A) use of GOLD or ATS/ERS guidelines,

(B) preference for electronic sources of medical information, (C) barriers to diagnose COPD, (D) how providers diagnose COPD, (E) diagnostic tests used to diagnose COPD, (F) satisfaction with symptom assessment, (G) use of the COPD Assessment Test (CAT) or modified Medical Research Council (mMRC) dyspnea scale to assess symptoms in clinic, $(\mathrm{H})$ satisfaction with access to spirometry, $(\mathrm{I})$ having an in-office spirometer and $(\mathrm{J})$ routine testing for alpha-1 antitrypsin.

COPD. The remaining 39\% reported that they used COPD guidelines, but could not remember their name (14\%), did not use guidelines (17\%), did not know there were any guidelines (4\%), or mistakenly used asthma guidelines instead (4\%) (Figure $1 \mathrm{~A}$ and
Supplementary Table 1 [in the online supplement]). Seventy-six percent of providers reported that electronic sources were the best way for them to access information to guide treatment of COPD patients, including online medical resources (48\%), 
electronic health record-based guideline prompts (15\%), and smartphone applications (13\%) (Figure $1 \mathrm{~B}$ and Supplementary Table 1 [in the online supplement]). Only $24 \%$ of providers preferred nonelectronic sources of information, such as printed guideline summaries (17\%), standing orders (3\%), or other sources (4\%).

Providers face many barriers to diagnosing COPD, but the most prominent are the presence of multiple chronic conditions, patient failure to recognize and report symptoms, and lack of easy access to spirometry (Figure $1 \mathrm{C}$ and Supplementary Table 1 [in the online supplement]). Eighty-nine percent of rural providers were aware that spirometry was needed to diagnose COPD, but they also relied upon a history of smoking, dyspnea at rest, dyspnea with activity, or the presence of a smoker's cough (Figure 1D and Supplementary Table 1 [in the online supplement]). Spirometry was the most common test used to diagnose COPD, but a chest X-ray, trial of an inhaled bronchodilator or inhaled corticosteroid were also used (Figure 1E and Supplementary Table 1 [in the online supplement]).

\section{Assessment}

Complete survey results for assessments are shown in Supplementary Table 2 (in the online supplement). Eighty-seven percent of providers were satisfied with their practices' ability to assess symptoms yet only $11 \%$ used a validated assessment tool, such as the CAT or the mMRC dyspnea scale (Figure $1 \mathrm{~F}-\mathrm{G}$ ). On the other hand, only $62 \%$ of providers were satisfied with their practices' ability to access spirometry and $66 \%$ had a spirometer in their office (Figure $1 \mathrm{H}$ -I). Screening for alpha-1 antitrypsin deficiency is recommended for everyone with airflow limitation by spirometry. ${ }^{30,32-34}$ The survey showed that only $1 \%$ of rural practices routinely test for alpha- 1 antitrypsin, $58 \%$ occasionally test, and $41 \%$ never test (Figure $1 \mathrm{~J}$ ).

\section{Treatment and Prevention}

A high proportion of providers were satisfied with their practices' ability to deliver smoking cessation counseling and inhaler education and treat symptoms and exacerbations, but fewer (66\%) were satisfied with their practices' ability to prevent exacerbations (Figure 2A-E and Supplementary Table 3 [in the online supplement]).

\section{Figure 2. Total Cohort Treatment, Prevention, and Access to Supportive Services}
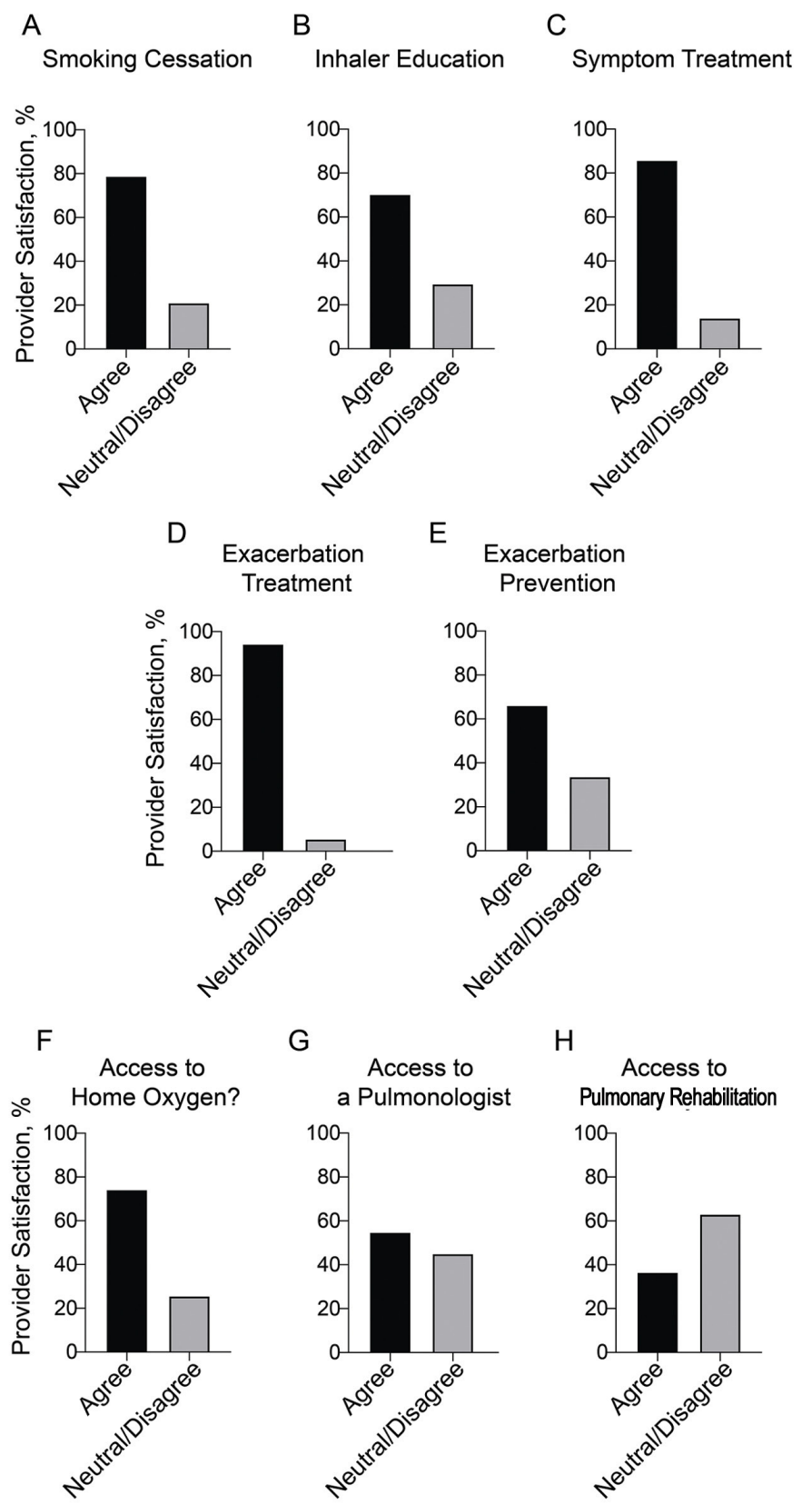

G

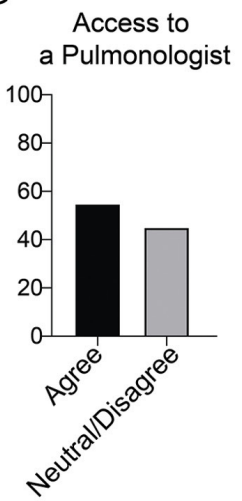

$\mathrm{H}$

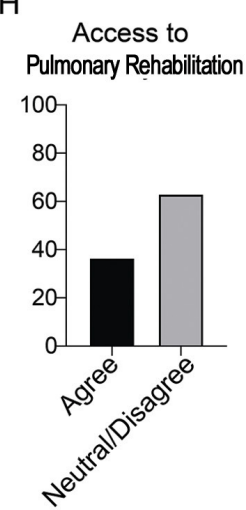

Survey questions are shown graphically after combining agree/strongly agree answers into the "agree" column and neutral/disagree/strongly disagree answers into the "neutral/disagree" column. Results show provider satisfaction with: (A) smoking cessation counseling, (B) delivery of inhaler education, (C) symptom treatment, (D) exacerbation treatment,

(E) exacerbation prevention; and patient access to: $(F)$ home oxygen,

$(\mathrm{G})$ a pulmonologist and $(\mathrm{H})$ pulmonary rehabilitation.

\section{Access to Supportive Services}

Most providers felt that their COPD patients had access to home oxygen therapy if needed (Figure 2F and Supplementary Table 4 [in the 
online supplement]). In contrast, only $55 \%$ of providers agreed that their patients had access to a pulmonologist for consultation, and only 37\% agreed that their patients had access to pulmonary rehabilitation (Figure 2G-H and Supplementary Table 4 [in the online supplement]).

\section{Subgroup Analyses}

Provider Training: To determine if professional training impacted survey answers, providers were divided and analyzed by training: physicians (MD or DO) and APPs (NP or PA). Although physicians were significantly more likely than APPs to feel that multiple chronic conditions were a barrier in the diagnosis of COPD ( $p=0.01)$, APPs tended to feel that lack of knowledge/training was a barrier in COPD diagnosis $(p=0.08)$ (Figure 3A-B). Physicians were more likely to use dyspnea with activity $(p=0.02)$ or dyspnea at rest $(p=0.08)$ to diagnose COPD, compared to APPs (Figure 3C-D). Otherwise, physicians and APPs were similar in terms of demographics and responses to survey questions (Table 1 and Supplementary Tables 1-4 [in the online supplement]).

Practice Location: To determine the effect of practice location on barriers to care delivery, providers were divided into 3 groups based on their state designation. Compared to providers in Colorado and Kansas, providers in the Other States group were more likely to have smaller practices $(p=0.03)$ (Table 1). Their practices also used less spirometry to diagnose COPD ( $p=0.03$ ) (Figure 3E), and fewer had a spirometer in their office $(p=0.04)$ (Figure 3F). Providers in the Other States group also felt that their patients had less access to pulmonologists $(p=0.02)$ or pulmonary rehabilitation ( $p=0.0007)$, compared to providers in Colorado and Kansas (Figures 3G-H). Responses to the remainder of the survey questions were similar (Table 1 and Supplementary Tables 1-4 [in the online supplement]).

Practice Population and Size: To determine whether practice population or size impacted survey answers, the total cohort was divided into those targeted to medically underserved areas or populations (i.e., FQHCs, RHCs and Indian Health Service) or not (i.e., private/hospital clinics), and small (i.e., $\leq 5$ providers) versus larger (i.e., $>5$ providers) practices. Sixty-two percent of providers worked in an FQHC or RHC and $38 \%$ worked in a private/hospital clinic. Fifty-two percent of providers worked in a smaller practice and $48 \%$ worked in a larger practice. Neither of these analyses revealed differences in provider demographics or responses (data not shown).

\section{Discussion}

Primary care providers are on the front line of care for COPD patients nationally. ${ }^{35}$ Given the paucity of pulmonary specialists in rural areas, ${ }^{16,17}$ the role of the primary care provider for rural COPD patients is paramount. ${ }^{34}$ Outcomes for rural COPD patients, such as mortality and hospitalizations, are worse than their urban counterparts in many respects. ${ }^{2,10-12}$ This is likely due to ongoing exposures (e.g., cigarette smoke, secondhand smoke, and agricultural dusts, fumes, and pesticides), ${ }^{7,9,35-39}$ as well as unique barriers that impede access to care. ${ }^{15,16}$ Poor outcomes may also be due to obstacles that prevent optimal delivery of care, but these barriers have received much less attention. ${ }^{20}$ Our study found significant challenges to diagnosis, assessment, prevention, and access to ancillary services that were affected by provider type and practice location, but not by the patient population served or practice size.

GOLD and ATS/ERS COPD guidelines are the primary sources of evidence-based information for the diagnosis and management of stable COPD and COPD exacerbations. ${ }^{30,31}$ Yawn et al assessed the use of GOLD or ATS/ERS guidelines in a group of mostly urban primary care medical providers attending continuing medical education conferences in 2014, and found that approximately $48 \%$ used COPD guidelines but that approximately 29\% were not aware of them. ${ }^{24}$ This study asked the same question and found that $61 \%$ of rural providers used GOLD or ATS/ERS guidelines and that $4 \%$ were unaware of them, suggesting that progress is being made.

Up to $60 \%$ of people with low lung function are unaware that they have obstructive lung disease, indicating that COPD is under-diagnosed in the United States. ${ }^{40}$ Under-diagnosis of COPD may be due to suboptimal communication between patients and providers, or inadequate knowledge about how to diagnose COPD. ${ }^{20}$ This survey showed that the ability of rural providers to diagnose COPD was impaired by the presence of multiple chronic conditions and the inability of patients to recognize 


\section{Figure 3. Survey Answers by Provider Type and Practice Location}

A

Multiple Chronic Conditions
are Barriers to Diagnose COPD

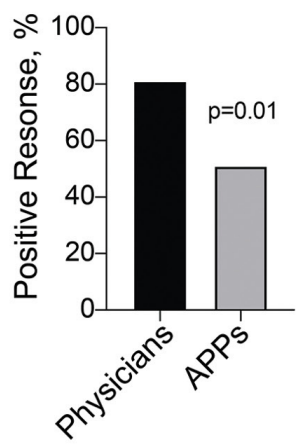

E

Use Spiromety to Diagnose COPD

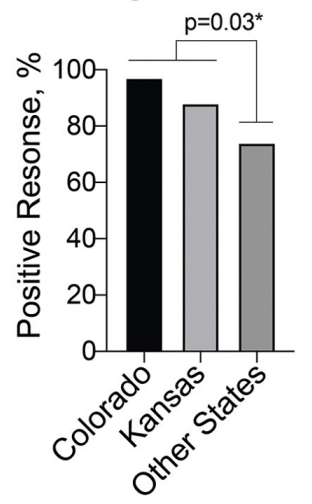

B
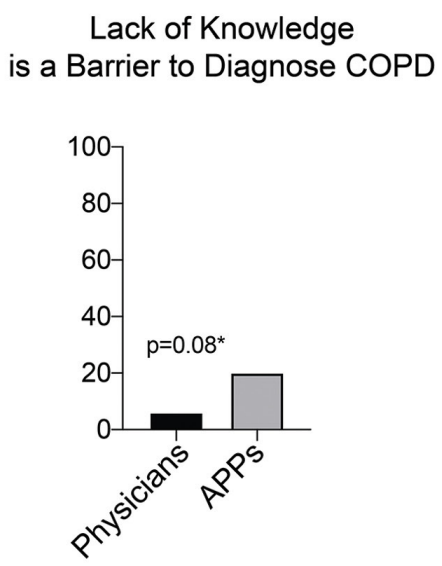

$\mathrm{F}$

Have a Spirometer is in the Office

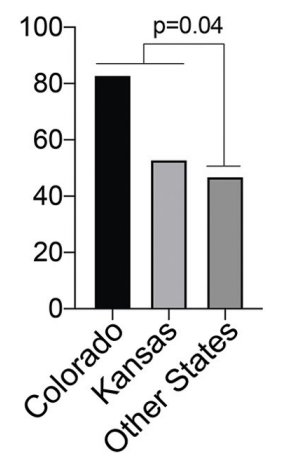

C
Use Dyspnea with Activity to Diagnose COPD

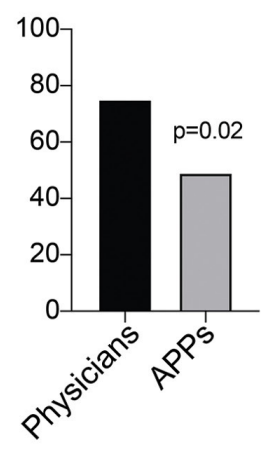

G

Satisfaction with Access to Pulmonologists

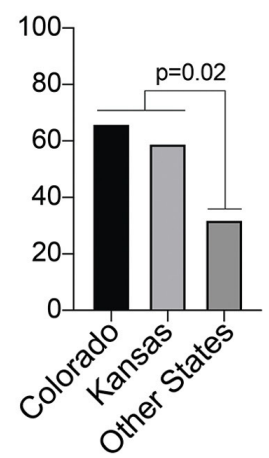

D

Use Dyspnea at Rest
to Diagnose COPD

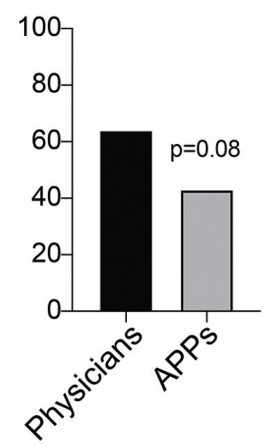

$\mathrm{H}$

Satisfaction with Access to Pulmonary Rehabilitation

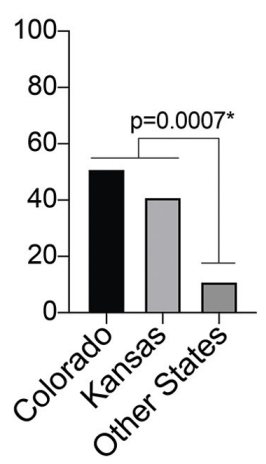

This figure shows selected survey responses by provider type (A-D) and practice location (E-H). Providers were divided by training into physicians with an MD or DO, and advanced practice providers (APPs) with an NP or PA (or other). Results show differences in how physicians or APPs viewed: (A) multiple chronic conditions or (B) lack of knowledge/training as barriers in the diagnosis of COPD. They also show differences in whether physicians or APPs use: (C) dyspnea with activity or D) dyspnea at rest in the diagnosis COPD. Providers were divided into 3 groups based on the state(s) where they practiced to determine the effect of practice location on delivery of care. Providers living in states with fewer responses and without a rural practice-based research network (i.e., Nevada, Utah, Wyoming, North Dakota, and Arizona) were combined into an "Other States" group. Results show differences in: (E) the use of spirometry to diagnose COPD and (F) whether providers have a spirometer in their office. They also show differences in satisfaction regarding access to: $\mathrm{G})$ a pulmonologist or to $(\mathrm{H})$ pulmonary rehabilitation. We considered providers to be satisfied if they agreed or strongly agreed with the statement. $P$-value indicates results of a Chi-square Test (or Fisher's Exact test ${ }^{\star}$ ) for comparison between MD/DO and APP groups or between Colorado and Kansas combined versus Other States.

and report symptoms, both of which make diagnosis more difficult. Almost all rural providers understand that spirometry is necessary to diagnose COPD, but it appears that access to spirometry is still a problem for many.

GOLD Guidelines recommend regular assessments of symptoms with the CAT or mMRC dyspnea scale because they relate to risk of exacerbation, acute deterioration in health status, depression, and death, and can be used to guide therapy. ${ }^{30,41}$ They can also be used to capture symptoms that may not be recognized or reported otherwise. ${ }^{30,42}$ The CAT is the preferred assessment tool because it assesses respiratory and non-respiratory symptoms, while the mMRC only assesses dyspnea. ${ }^{30}$ Study findings indicate that only $11 \%$ of rural providers use the CAT or the mMRC dyspnea scale to assess symptoms, but that $87 \%$ were satisfied with their ability to assess symptoms. The reason(s) that the CAT or mMRC have not been integrated into routine assessment is not known, but possibilities include the perception that it is difficult to incorporate an assessment tool 
into a busy practice, providers may not be aware of this recommendation, or providers may trust their ability to assess symptoms already. In this context, implementation of the CAT or $\mathrm{MMRC}$ as a routine clinic measurement may help providers identify patients who fail to recognize and report symptoms, which was noted to be a barrier to COPD diagnosis by $52 \%$ of providers.

The study revealed that $58 \%$ of providers occasionally test for alpha-1 antitrypsin deficiency and that $41 \%$ never test. In Europe, approximately 24\% of general practitioners, $34 \%$ of internists, and $73 \%$ of pulmonologists surveyed said that they "currently test for alpha- 1 antitrypsin deficiency," 43 and testing was directly related to knowledge about the disease. ${ }^{43,44}$ Alpha-1 antitrypsin deficiency has been recognized as a risk factor for COPD since $1963^{45,46}$ and is present in $1 \%-2 \%$ of COPD patients within the United States. ${ }^{4,48}$ Identification that a person is deficient allows for smoking cessation efforts, identification of affected family members, and replacement therapy in select patients. ${ }^{47}$ The World Health Organization, the ATS/ERS, and GOLD guidelines recommend that all patients with fixed airflow obstruction (e.g., COPD and asthma) or unexplained liver disease be tested for alpha-1 antitrypsin deficiency, with or without the presence of an additional COPD risk factor such as smoking. ${ }^{30,32-34}$ Despite these recommendations, diagnosis is frequently delayed and $>85 \%$ are estimated to have not yet been recognized. ${ }^{47,49}$ Novel approaches to increase alpha- 1 antitrypsin screening would identify increased numbers of deficient patients and provide new avenues for treatment of patients and knowledge for families. ${ }^{50-52}$

Rural COPD patients have decreased access to pulmonary specialists and pulmonary rehabilitation, $4,5,17,25$ but less is known about whether rural providers perceive this deficiency. This is an important distinction, because many rural providers have multidisciplinary training in Family Medicine, are comfortable caring for complex patients, and may not feel the need for these services. Our survey found that $45 \%$ of rural providers were dissatisfied with their patients' access to pulmonologists. Croft et al examined geographic access to pulmonologists and found that $65 \%$ of rural COPD patients do not have access to a pulmonologist within a 10 -mile buffer distance. ${ }^{17}$ Therefore, it appears that provider dissatisfaction with access to a pulmonologist (i.e., $45 \%$ ) is roughly similar to the geographic lack of access for patients (i.e., 65\%). Kim et al also demonstrated a link between pulmonary specialty care and reduced hospital/emergency department visits for COPD. ${ }^{16}$ Novel mechanisms to move knowledge to rural primary care providers instead of moving patients, ${ }^{4,53,54}$ and/or to increase remote access to pulmonary specialty care, might help to alleviate this gap in rural settings. ${ }^{55-58}$

The study also found that only $37 \%$ of rural providers were satisfied with access to pulmonary rehabilitation. This contrasts with the National Heart, Lung, and Blood Institute national survey which found that $74 \%$ of non-urban primary care physicians reported that rehabilitation programs were "available" to their patients. ${ }^{20}$ Our results suggest that availability of pulmonary rehabilitation may be worse in the western United States where distances are greater than they are nationwide. Difficulty with transportation, distance, and location of programs have been identified as major factors with both attendance and completion of pulmonary rehabilitation. ${ }^{59,60}$ Increasing community- ${ }^{19}$ and home-based pulmonary rehabilitation programs ${ }^{61,62}$ or remote programs that have components of pulmonary rehabilitation ${ }^{55-58}$ may help to overcome these hurdles.

To determine whether provider responses varied by location, participants were separated into 3 groups based on their residence in Colorado, Kansas, or "Other States" that individually had a lower number of survey responses and were not associated with a rural PBRN. Providers in the Other States group worked in smaller practices, used less spirometry to diagnose COPD, were less likely to have a spirometer in their office, and had less access to pulmonologists and to pulmonary rehabilitation compared to providers in Colorado and Kansas. Smaller practices, worse access to ancillary services, and lack of statewide PBRNs to bind practices together, ${ }^{63}$ suggest that providers in these states may be less supported.

This study has several limitations, some with potential importance for future, rural clinical studies. First, only 77 providers responded to the survey out of approximately 1018 who had access to the survey through newsletters and emails without incentives, resulting in an $8 \%$ response rate. This response rate is low but is similar to the $8 \%-9.7 \%$ response rate for surveys sent to pharmacists by email only. ${ }^{29}$ 
Eberth et al also obtained a $13 \%$ response rate from a national cancer screening survey that was sent to primary care physicians by 3 mailings, 1 email follow-up, and incentives. ${ }^{64}$ Because distribution methods for our survey utilized newsletters, we can only estimate the number of providers that had access to the survey and not the number who saw the survey, which could make the responses appear artificially low. The response rate may also be low because of the coronavirus disease 2019 (COVID-19) pandemic. Non-PBRN providers were contacted from February through April of 2020, as the COVID-19 pandemic took hold in the United States. The pandemic prevented recruitment of additional PBRNs to the study and may have decreased responses from providers, especially those living in non-PBRN states. An estimated 110 responses were needed to yield a \pm 10 percentage point accuracy in estimation of the percentage of rural providers using GOLD or ATS/ERS COPD guidelines. The Rural Medical Provider COPD Survey showed that $61 \%$ of rural medical providers use COPD guidelines, which was 13 percentage points higher than a national sample of primary care providers from 2014, which exceeded our estimates. ${ }^{24}$

Second, survey distribution methods might have impacted results and numbers of responders. Seventy-three percent of providers were recruited from rural primary care PBRNs in Colorado and Kansas, while $27 \%$ were recruited primarily through SORHs in Nevada, Utah, Wyoming, North Dakota, and Arizona. ${ }^{27}$ Fewer survey responses were noted from non-PBRN states (3.5\%) versus PBRN states (11\%). Delivery of the survey though PBRNs versus SORHs could have influenced both distribution numbers and provider type. These results could also reflect real differences in states with different levels or types of support for providers. Third, the low number of responses is a concern for generalizability, but it is reassuring that the pattern of responses to questions 1-4 was similar to identical questions included in 2 national surveys of primary care providers by Yawn et al. ${ }^{23,24}$

Additional limitations might be related to: the self-identification of rural and non-rural providers causing surveys to be inadvertently sent to non-rural providers, no financial compensation mechanism, and small response numbers not adequately representing rural providers in each state. Because survey data was self-reported, results were also subject to social demand and recall biases. Selection bias may have occurred, because only electronic surveys were received. The survey did not address barriers or challenges related to access to health insurance, geographic barriers, or ability to afford medications. It also did not address barriers to care faced by COPD patients in rural areas, which is an equally important question to address.

COPD in rural areas of the United States is plagued by high prevalence, poor outcomes, and excess mortality compared with urban areas of the country. ${ }^{2,4-13}$ The reasons for these disparities are complex, but likely relate in part to important challenges faced by rural medical providers as they work to deliver the best care to COPD patients. ${ }^{18-20}$ The Rural Medical Provider COPD Survey identified bright spots in the increased, but not yet optimal, use of COPD guidelines to manage COPD and the high use of spirometry to diagnose COPD. But it also identified deficits in the assessment of symptoms and alpha-1 antitrypsin, prevention of exacerbations, and access to pulmonary specialty care and pulmonary rehabilitation that could be targeted for improvement. The survey also presents intriguing data suggesting that there may be regional/state differences, which could relate to expansive geography and/or the presence of a rural PBRN. It is also possible that the presence or absence of a PBRN is a marker for variable levels of provider support. Ultimately, as articulated by Westfall et al, rural primary care practices are important laboratories to ask fundamental questions about how best to implement recommendations derived from academic studies. ${ }^{63}$ In this context, it is important to remember that "the final crucial step in clinical care is the delivery of recommended care to the right patient at the right time, resulting in improvement in that patient's health," 63 and this is not always easy or straightforward. The results of this survey create opportunities for improvement through action.

\section{Acknowledgements}

We would like to extend our deep appreciation to the rural providers who participated in this study, to the PBRNs in Colorado and Kansas, and to the SORHs in Nevada, Utah, Wyoming, North Dakota, and Arizona for their help recruiting rural medical providers. We are also grateful to lay members of the Community 
Advisory Council in Colorado who helped design the survey.

Author contributions: RWV, FDV, PBK, and SJM had full access to all of the data in the study and take responsibility for the integrity of the data and the accuracy of the data analysis. RWV, FDV, PBK, KAG, TKO, LZ, DHF, AN, DEN, EJM, CG, and JLN contributed to the study concept. FDV, PBK, LZ, TKO, LZ, DHF, AN, KMT, DEN, EJM, KAG, and RWV contributed to acquisition of data. FDV, PBK, SJM, TKO, LZ, KMT, AN, DEN, EJM, KAG, and RWV contributed to analysis and interpretation of data. FDV, PBK, SJM, TKO, LZ, KMT, JLN, CG, KAG, and RWV drafted the manuscript. FDV, PBK, JKZ, TKO, LZ, KMT, DHF, AN, DEN, EJM, JLN, CG, KAG, and RWV contributed to critical revision of the manuscript for important intellectual content. SJM, FDV, and RWV performed statistical analysis. FDV, PBK, JKZ, and RWV provided administrative, technical, or material support. RWV supervised the study.

\section{Declaration of Interest}

The authors have nothing to declare. 


\section{References}

1. National Heart, Lung, and Blood Institute (NHLBI). COPD National Action Plan. NHLBI website. Published February 2018. Updated February 2021. Accessed July 2020. https://www.nhlbi.nih.gov/ health-topics/all-publications-and-resources/copd-national-actionplan

2. Croft JB, Wheaton AG, Liu Y, et al. Urban-rural county and state differences in chronic obstructive pulmonary disease - United States, 2015. MMWR Morb Mortal Wkly Rep. 2018;67(7):205-211. doi: https://doi.org/10.15585/mmwr.mm6707a1

3. Murphy SL, Xu J, Kochanek KD, Arias E. Mortality in the United States, 2017. NCHS Data Brief. 2018;(328).

https://www.cdc.gov/nchs/products/databriefs/db328.htm

4. Moore P, Atkins GT, Cramb S, et al. COPD and rural health: a dialogue on the national action plan. J Rural Health. 2019;35(4):424-428. doi: https://doi.org/10.1111/jrh.12346

5. Mushtaq A. COPD and rural health in the USA. Lancet Respir Med. 2018;6(5):330-331.

doi: https://doi.org/10.1016/S2213-2600(18)30142-5

6. Raju S, Brigham EP, Paulin LM, et al. The burden of rural chronic obstructive pulmonary disease: analyses from the national health and nutrition examination survey. Am $J$ Respir Crit Care Med. 2020;201(4):488-491.

doi: https://doi.org/10.1164/rccm.201906-1128LE

7. Raju S, Keet CA, Paulin LM, et al. Rural residence and poverty are independent risk factors for chronic obstructive pulmonary disease in the United States. Am J Respir Crit Care Med. 2019;199(8):961-969. doi: https://doi.org/10.1164/rccm.201807-13740C

8. American Lung Association (ALA). Top 10 populations disproportionately affected by cigarette smoking and tobacco use. ALA website. Published January 2020.Updated January 27, 2021. Accessed July 2020. https://www.lung.org/research/sotc/by-thenumbers/top-10-populations-affected

9. Centers for Disease Control and Prevention (CDC). Tobacco use by geographic region. CDC website. Published November 2019. Accessed July 2020. https://www.cdc.gov/tobacco/disparities/geographic/ index.htm

10. Burkes RM, Gassett AJ, Ceppe AS, et al. Rural residence and COPD exacerbations: analysis of the SPIROMICS cohort. Ann Am Thorac Soc. 2018;15(7):808-816.

doi: https://doi.org/10.1513/AnnalsATS.201710-837OC

11. Jackson BE, Coultas DB, Suzuki S, Singh KP, Bae S. Rural-urban disparities in quality of life among patients with COPD. J Rural Health. 2013;29(Suppl 1):s62-s69. doi: https://doi.org/10.1111/jrh.12005

12. Abrams TE, Vaughan-Sarrazin M, Fan VS, Kaboli PJ. Geographic isolation and the risk for chronic obstructive pulmonary diseaserelated mortality: a cohort study. Ann Intern Med. 2011;155(2):80-86. doi: https://doi.org/10.7326/0003-4819-155-2-201107190-00003
13. Garcia MC, Faul M, Massetti G, et al. Reducing potentially excess deaths from the five leading causes of death in the rural United States. MMWR Surveill Summ. 2017;66(2):1-7.

doi: https://doi.org/10.15585/mmwr.ss6602a1

14. Moy E, Garcia MC, Bastian B, et al. Leading causes of death in nonmetropolitan and metropolitan areas - United States, 1999-2014. MMWR Surveill Summ. 2017;66(1):1-8.

doi: https://doi.org/10.15585/mmwr.ss6601a1

15. Douthit N, Kiv S, Dwolatzky T, Biswas S. Exposing some important barriers to health care access in the rural USA. Public Health. 2015;129(6):611-620.

doi: https://doi.org/10.1016/j.puhe.2015.04.001

16. Kim M, Ren J, Tillis W, Asche CV, Kim IK, Kirkness CS. Explaining the link between access-to-care factors and health care resource utilization among individuals with COPD. Int JChron Obstruct Pulmon Dis. 2016;11:357-367. doi: https://doi.org/10.2147/COPD.S95717

17. Croft JB, Lu H, Zhang X, Holt JB. Geographic accessibility of pulmonologists for adults with COPD: United States, 2013. Chest. 2016;150(3):544-553.

doi: https://doi.org/10.1016/j.chest.2016.05.014

18. Brems C, Johnson ME, WarnerTD, Roberts LW. Barriers to healthcare as reported by rural and urban interprofessional providers. J Interprof Care. 2006;20(2):105-118.

doi: https://doi.org/10.1080/13561820600622208

19. Doyle D, Tommarello C, Broce M, Emmett M, Pollard C. Implementation and outcomes of a community-based pulmonary rehabilitation program in rural Appalachia. $J$ Cardiopulm Rehabil Prev. 2017;37(4):295-298.

doi: https://doi.org/10.1097/HCR.0000000000000247

20. National Heart, Lung, and Blood Institute (NHLBI). COPD: tracking perceptions of the individuals affected and the providers who treat them (2018). NHLBI website. Published February 2019. Accessed July 2020. https://www.nhlbi.nih.gov/health-topics/all-publications-andresources/copd-tracking-perceptions-individuals-affected-and

21. Perez X, Wisnivesky JP, Lurslurchachai L, Kleinman LC, Kronish IM. Barriers to adherence to COPD guidelines among primary care providers. Respir Med. 2012;106(3):374-381. doi: https://doi.org/10.1016/j.rmed.2011.09.010

22. Criner RN, Han MK. COPD care in the 21st century: a public health priority. Respir Care. 2018;63(5):591-600.

doi: https://doi.org/10.4187/respcare.06276

23. Yawn BP, Wollan PC. Knowledge and attitudes of family physicians coming to COPD continuing medical education. Int J Chron Obstruct Pulmon Dis. 2008;3(2):311-317. doi: https://doi.org/10.2147/COPD.S2486

24. Yawn BP, Wollan PC, Textor KB, Yawn RA. Primary care physicians', nurse practitioners' and physician assistants' knowledge, attitudes, and beliefs regarding COPD: 2007 to 2014. Chronic Obstr Pulm Dis. 2016;3(3):628-635.

doi: https://doi.org/10.15326/jcopdf.3.3.2015.0168 
25. Barr RG, Celli BR, Martinez FJ, et al. Physician and patient perceptions in COPD: the COPD resource network needs assessment survey. Am JMed. 2005;118(12):1415.

doi: https://doi.org/10.1016/j.amjmed.2005.07.059

26. Davis KJ, Landis SH, Oh YM, et al. Continuing to confront COPD international physician survey: physician knowledge and application of COPD management guidelines in 12 countries. Int J Chron Obstruct Pulmon Dis. 2015;10(1):39-55. doi: https://doi.org/10.2147/COPD.S70162

27. Health Resources and Services Administration (HRSA). Rural hospital programs. HRSA website. Published 2020. Updated April 2021. Accessed September 2020.

https://www.hrsa.gov/rural-health/rural-hospitals

28. Research Electronic Data Capture (REDCap). REDCap: about. REDCap website. Published 2020. Accessed September 2020. https://projectredcap.org/about/

29. Hardigan PC, Popovici I, Carvajal MJ. Response rate, response time, and economic costs of survey research: a randomized trial of practicing pharmacists. Res Social Adm Pharm. 2016;12(1):141-148. doi: https://doi.org/10.1016/j.sapharm.2015.07.003

30. Global Initiative for Chronic Obstructive Lung Disease (GOLD). Global strategy for the diagnosis, management, and prevention of chronic obstructive pulmonary disease. GOLD website. Published 2020. Accessed October 2020. http://goldcopd.org

31. Qaseem A, Wilt TJ, Weinberger SE, et al. Diagnosis and management of stable chronic obstructive pulmonary disease: a clinical practice guideline update from the American College of Physicians, American College of Chest Physicians, American Thoracic Society, and European Respiratory Society. Ann Intern Med. 2011;155(3):179-191. doi: https://doi.org/10.7326/0003-4819-155-3-201108020-00008

32. Alpha-1 antitrypsin deficiency: memorandum from a WHO meeting. Bull World Health Organ. 1997;75(5):397-415.

33. American Thoracic Society, European Respiratory Society. American Thoracic Society/European Respiratory Society statement: standards for the diagnosis and management of individuals with alpha-1 antitrypsin deficiency. Am J Respir Crit Care Med. 2003;168(7):818900. doi: https://doi.org/10.1164/rccm.168.7.818

34. Miravitlles M, Dirksen A, Ferrarotti I, et al. European Respiratory Society statement: diagnosis and treatment of pulmonary disease in alpha1-antitrypsin deficiency. Eur Respir J. 2017;50(5):1700610. doi: https://doi.org/10.1183/13993003.00610-2017

35. Han MK, Martinez CH, Au DH, et al. Meeting the challenge of COPD care delivery in the USA: a multiprovider perspective. Lancet Respir Med. 2016;4(6):473-526.

doi: https://doi.org/10.1016/S2213-2600(16)00094-1

36. Alif SM, Dharmage SC, Benke G, et al. Occupational exposure to pesticides are associated with fixed airflow obstruction in middle-age. Thorax. 2017;72(11):990-997.

doi: https://doi.org/10.1136/thoraxjnl-2016-209665
37. Doney BC, Henneberger PK, Humann MJ, Liang X, Kelly KM, CoxGanser JM. Occupational exposure to vapor-gas, dust, and fumes in a cohort of rural adults in Iowa compared with a cohort of urban adults. MMWR Surveill Summ. 2017;66(21):1-5. doi: https://doi.org/10.15585/mmwr.ss6621a1

38. Matheson MC, Benke G, Raven J, et al. Biological dust exposure in the workplace is a risk factor for chronic obstructive pulmonary disease. Thorax. 2005;60(8):645-651. doi: https://doi.org/10.1136/thx.2004.035170

39. Jenkins WD, Matthews AK, Bailey A, et al. Rural areas are disproportionately impacted by smoking and lung cancer. Prev Med Rep. 2018;10:200-203.

doi: https://doi.org/10.1016/j.pmedr.2018.03.011

40. Mannino DM, Gagnon RC, Petty TL, Lydick E. Obstructive lung disease and low lung function in adults in the United States: data from the National Health and Nutrition Examination Survey, 19881994. Arch Intern Med. 2000;160(11):1683-1689. doi: https://doi.org/10.1001/archinte.160.11.1683

41. Karloh M, Fleig Mayer A, Maurici R, Pizzichini MMM, Jones PW, Pizzichini E. The COPD assessment test: what do we know so far?: a systematic review and meta-analysis about clinical outcomes prediction and classification of patients into GOLD stages. Chest. 2016;149(2):413-425. doi: https://doi.org/10.1378/chest.15-1752

42. Jones PW, Harding G, Wiklund I, et al. Tests of the responsiveness of the COPD assessment test following acute exacerbation and pulmonary rehabilitation. Chest. 2012;142(1):134-140. doi: https://doi.org/10.1378/chest.11-0309

43. Greulich T, Ottaviani S, Bals R, et al. Alpha-1 antitrypsin deficiencydiagnostic testing and disease awareness in Germany and Italy. Respir Med. 2013;107(9):1400-1408. doi: https://doi.org/10.1016/j.rmed.2013.04.023

44. Greulich T, Vogelmeier CF. Alpha-1 antitrypsin deficiency: increasing awareness and improving diagnosis. Ther Adv Respir Dis. 2016;10(1):72-84.

doi: https://doi.org/10.1177/1753465815602162

45. Laurell C-B, Eriksson A. The electrophoretic alpha-1 globulin pattern of serum in alpha-1 antitrypsin deficiency. Scand J Clin Lab Invest. 1963;15(2):132-140. doi: https://doi.org/10.1080/00365516309051324

46. Carrell RW. What we owe to alpha (1)-antitrypsin and to Carl-Bertil Laurell. COPD. 2004;1(1):71-84. doi: https://doi.org/10.1081/COPD-120028703

47. Wells AD, Woods A, Hilleman DE, Malesker MA. Alpha-1 antitrypsin replacement in patients with COPD. PT. 2019;44(7):412-415.

48. Rahaghi FF, Sandhaus RA, Brantly ML, et al. The prevalence of alpha-1 antitrypsin deficiency among patients found to have airflow obstruction. COPD. 2012;9(4):352-358. doi: https://doi.org/10.3109/15412555.2012.669433 
49. Silverman EK, Sandhaus RA. Alpha-1 antitrypsin deficiency. N Engl $J$ Med. 2009;360(26):2749-2757. doi: https://doi.org/10.1056/NEJMcp0900449

50. Jain A, McCarthy K, Xu M, Stoller JK. Impact of a clinical decision support system in an electronic health record to enhance detection of alpha (1)-antitrypsin deficiency. Chest. 2011;140(1):198-204. doi: https://doi.org/10.1378/chest.10-1658

51. Stoller JK. Detecting alpha-1 antitrypsin deficiency. Ann Am Thorac Soc. 2016;13(Suppl 4):S317-325. doi: https://doi.org/10.1513/AnnalsATS.201506-349KV

52. Brantly M, Campos M, Davis AM, et al. Detection of alpha-1 antitrypsin deficiency: the past, present and future. Orphanet $J$ Rare Dis. 2020;15(1):96.

doi: https://doi.org/10.1186/s13023-020-01352-5

53. Arora S, Thornton K, Murata G, et al. Outcomes of treatment for hepatitis C virus infection by primary care providers. $N$ Engl $J$ Med. 2011;364(23):2199-2207.

doi: https://doi.org/10.1056/NEJMoa1009370

54. Socolovsky C, Masi C, Hamlish T, et al. Evaluating the role of key learning theories in ECHO: a telehealth educational program for primary care providers. Prog Community Health Partnersh. 2013;7(4):361-368. doi: https://doi.org/10.1353/cpr.2013.0043

55. Koff PB, Jones RH, Cashman JM, Voelkel NF, Vandivier RW. Proactive integrated care improves quality of life in patients with COPD. Eur Respir J. 2009;33(5):1031-1038. doi: https://doi.org/10.1183/09031936.00063108

56. Linderman DJ, Koff PB, Freitag TJ, Min SJ, Vandivier RW. Effect of integrated care on advanced chronic obstructive pulmonary disease in high-mortality rural areas. Arch Intern Med. 2011;171(22):2059-2061. doi: https://doi.org/10.1001/archinternmed.2011.576

57. Vandivier RW, Linderman DJ, Koff PB. A comprehensive care management program to prevent chronic obstructive pulmonary disease hospitalizations. Ann Intern Med. 2012;157(7):530. doi: https://doi.org/10.7326/0003-4819-157-7-201210020-00018

58. Koff PB, Min SJ, Freitag TJ, et al. Impact of proactive integrated care on chronic obstructive pulmonary disease. Chronic Obstr Pulm Dis. 2021;8(1):100-116. doi: https://doi.org/10.15326/jcopdf.2020.0139

59. Keating A, Lee A, Holland AE. What prevents people with chronic obstructive pulmonary disease from attending pulmonary rehabilitation? A systematic review. Chron Respir Dis. 2011;8(2):8999. doi: https://doi.org/10.1177/1479972310393756

60. Sabit R, Griffiths TL, Watkins AJ, et al. Predictors of poor attendance at an outpatient pulmonary rehabilitation programme. Respir Med. 2008;102(6):819-824.

doi: https://doi.org/10.1016/j.rmed.2008.01.019
61. Holland AE, Mahal A, Hill CJ, et al. Home-based rehabilitation for COPD using minimal resources: a randomised, controlled equivalence trial. Thorax. 2017;72(1):57-65. doi: https://doi.org/10.1136/thoraxjnl-2016-208514

62. Maltais F, Bourbeau J, Shapiro S, et al. Effects of home-based pulmonary rehabilitation in patients with chronic obstructive pulmonary disease: a randomized trial. Ann Intern Med. 2008;149(12):869-878.

doi: https://doi.org/10.7326/0003-4819-149-12-200812160-00006

63. Westfall JM, Mold J, Fagnan L. Practice-based research-"Blue Highways" on the NIH roadmap. JAMA. 2007;297(4):403-406. doi: https://doi.org/10.1001/jama.297.4.403

64. Eberth JM, McDonnell KK, Sercy E, et al. A national survey of primary care physicians: perceptions and practices of low-dose CT lung cancer screening. Prev Med Rep. 2018;11:93-99. doi: https://doi.org/10.1016/j.pmedr.2018.05.013 